\title{
Controversy over the Policy of Network Neutrality and Analysis of the Development Status Quo of Developed Countries
}

\author{
Meijuan $\mathrm{Li}^{\mathrm{a}}$, Lei Hou ${ }^{\mathrm{b}}$ \\ ${ }^{\text {a }}$ School of Economics and Management, Yunnan Normal University \\ Kunming and 650500, China \\ ${ }^{\mathrm{b}}$ School of Economics and Management, Yunnan Normal University \\ Kunming and 650500, China
}

\begin{abstract}
In recent years, whether to implement "Network Neutrality" has been a very controversial topic in the Internet industry. Because of the huge impact that network neutrality policies have on the development of both the Internet industry and the interests of its related participants, not only academics but people from the practice community are intensively discussing this hot issue. Based on the content of network neutrality, as well as the current debate on network neutrality, from the aspects of supporters and objectors of network neutrality respectively, this paper analyzes the status quo of the development of network neutrality policies in major developed countries such as the United States and the United Kingdom, and finds that the parties involved have not yet reached a final conclusion on this dispute due to distinct opinions from different stakeholders on network neutrality policies. It is expected that future network neutral discussions will continue to deepen.
\end{abstract}

Keywords-Network neutrality; Internet; Content provider; Discrimination

\section{INTRODUCTION}

The Internet, as a means of transmission content and communication, should be open and fair, free and equal for all, and any user can use it at any time without worrying about experiencing different flow speeds due to different content. Through the use of network resources, obtaining the required content and services are equal. With the changes in the competitive landscape of the Internet industry, the continuous emergence of a large number of content providers has led to the gradual collapse of Internet operators' platforms into a purely data-transportation channel. Most of the profits are intercepted by content providers, and some content providers are acquiring faster data. So some of the content providers may construct a kind of contract to obtain a special channel from operator platform for faster network speed so that their content is transmitted first, and then users can get a better experience to achieve the purpose of attracting more users. Also, some Internet operator platforms are constantly developing their content products to share the profits of users. At the same time, to achieve market share, they try to shield some of the services provided by competitors, infringing other content providers' interests. In this context, the concept of network neutrality began to take shape.

\section{THE CONNOTATION OF NETWORK NEUTRALITY}

Regarding the problem of network neutrality, many foreign scholars have given different opinions. One of the earliest words of network neutrality originated from the first comment made by the US Federal Communications Commission to the Broadband Users and Innovation Alliance in the United States in November 2001. The organization believed that the Federal Communications Commission (FCC) should take some measures to prevent network operators from discriminating against various application sites, services, and devices that were not affiliated with the network operator should maintain the neutrality of the network. There is not a unified concept of network neutrality [1]. At present, there are four main viewpoints about the concept of network neutrality in academic circles:

First, Prof. Wu Xiuming advocates the non-discriminatory of network neutrality. According to his viewpoints, net neutrality has the following conceptual expressions: "Freedom, fairness, and openness are the core of network value," in which the network should be based on the elimination of various types of control and discrimination and establish a free development platform that is integrated, innovative, and open.

Second, on the basis that there is no exclusivity in the service agreement, the operator platform can charge additional fees for premium content providers, and its limited layered services and discrimination are also allowed. Take the United States as an example. Local legislators have proposed that as long as the operator platform does not charge special fees for higher quality service requirements, it allows the operator platform to differentiate between different content providers [2]

Thirdly, if the service agreement is not exclusive, the operator platform can charge premium content providers additional fees, and its limited layered services and discrimination are also permitted by the founder of the World Wide Web, Tim Berners-Lee. Tim Berners-Lee agrees with this view and gives his own opinion, "If I and other content providers pay a certain network fee for the network operator at 
the same time, and the payment price is high or low, then the operator platform can provide differentiated network access services based on the content provider's fee payment, and there is no repulsiveness between different services."

Fourth, implementing principle of the the first-come and first-served service. That is, a neutral network should not consider the quality of the transmitted content but should treat the service based on the principle that the data packet is on a first-come and first-served basis.

This article will use Gao Bin's (2008) view of the definition of network neutrality: Network neutrality, also known as "nondiscriminatory interconnection," includes two layers of meaning: First, dominant Internet operators in the market must not discriminate when interconnecting with other operators. Second, no discriminatory treatment of different content providers transmitted over the network, i.e. no prioritized service [3].

\section{CONTROVERSY OVER NETWORK NEUTRALITY POLICY}

The core value of the concept of network neutrality lies in promoting that the operator network can effectively serve all users and at the same time ensure the fairness and freedom of content, services, and applications enjoyed by users. However, in the early days of the Internet development, there was no contradiction between these principles, mainly because many functions of the Internet market had not been perfected at the time. Therefore, as a communication channel for transmitting data, the network could easily achieve non-discriminatory interconnection and interoperability. With the continuous increase of investment by operators, the gradual maturity of Internet technologies and the popularization and application of various applications, the original profit model of operators' platforms have been affected, and some leading content providers have obtained most of the profits in the Internet market.

With the explosive growth of various applications, the original bandwidth resources can no longer meet the huge demand for data transmission [4]. This has led to the emergence of problems. The first problem is that operator platforms need to increase investment to increase the carrying capacity of bandwidth. The second problem is, although the increase in user size has brought a huge market share, the operator platform has not obtained more profits from it, and it is unable to make up for its huge construction investment. Therefore, the operator platform points the finger to content providers. Network-neutral disputes begin to intensify, and different stakeholders hold different attitudes.

\section{A. The Supporters of Network Neutral}

Current support for network neutrality policy includes content providers (such as Google, Amazon, Yahoo, etc.) and $\mathrm{P} 2 \mathrm{P}$ (such as Skype, Vonage) and some terminal content providers. They believe that Internet service providers such as telecom operators and cable companies, should treat all data flow passing through their networks in a fair and equal manner and should not discriminate against them for discrimination. The content provider holds unanimous objections to the behavior of network operators providing flow services in an unfair way. For example, establishing a fast-track channel and discriminating against data flow can easily lead content providers to take corresponding actions to free users from allround blocking. Specifically, the main views of neutral network advocates are as follows:

\section{1) Flow control}

The cause of network neutrality is the network congestion caused by the explosion of transmission data flow. Supporters hope that they can use legal means and ensure for authorizing network operators and limited television companies, which can ensure that it can provide free communication channels, thus ensure the neutrality of the network. Winton Cerf, the founder of the Internet, concurred with this proposal. He believes that if the network operator has set some impediment or discrimination against the data flow transmitted to the channel, and when the law allows this to happen, this will seriously affect the development of health and efficiency, and it is unfavorable for the entire Internet industry. Therefore, a rational and effective network neutrality regulation policy is indispensable."

\section{2) No difference to content services}

Due to the characteristics of the Internet itself, the design of the Internet is based on the principle of end-to-end and the principle of utmost effort. The Internet must maintain the principle of fairness and openness and should abide by the above two basic principles, namely, ensuring that data and content can be requested by the shortest path. Freely transmitted by the sender to the recipient, ensuring that the data is treated fairly [5]. However, when the Internet turns to TCP/IP, QoS (Quality of Service) continues to occur. IPV4 (Internet protocol version 4) allows routers to prioritize the transmission of data in queues based on the ToS (Top of Service). To provide QoS services.

In addition to limiting the operational platform to adopt QoS policies for content providers' content services, the connotation of equal treatment of content services also includes the provision of differentiated QoS services on a forbidden basis. According to this principle, proponents have put forward the following theoretical basis:

First, due to the existence of positive network externalities, when the number of users of a certain content provider increases, not only the utility of the original user of the application will be improved, but also the use effect of other highly relevant users will benefit. However, if the QoS-based pricing approach is implemented, the operator platform will often ignore the existence of network externalities, so that based on the principle of maximizing self-interest, a price far higher than the overall optimal interest level will be established, 
which will restrict the healthy development of the entire Internet market.

Secondly, by implementing QoS pricing methods, the barriers to entry in the application market will be continuously increased, which will increase the monopoly position of the leading companies in the market. This will curb the entry and development of some small businesses with an innovative spirit and limit the market's creative development, and then evolved into a vicious competition.

Third, as the vertical integration of operators' platforms deepens, the products and services they provide gradually compete with the content providers'. Based on the principle of profit maximization, each operator platform may form a coalition to suppress content providers. Therefore, prohibiting the implementation of QoS pricing will prevent the operator platform from this opportunity.

Fourth, based on the priority of QoS payment, the operator platform may damage the unpaid customers to ensure the interests of high-paid content providers, making these customers pay for them.

\section{3) Principles of competition and innovation}

Supporters of network neutrality believe that it is indispensable to ensure that the Internet market is effective, fair, and open. Through the establishment of a regulatory agency, it is possible to promote the development of Internet innovation services and thus ensure the healthy and sustainable development of the Internet industry. Although increased investment and continuous promotion of new technologies and new products can promote the stable development of the Internet market, this does not mean sacrificing the interests of content providers and users [6]. The discriminatory pricing behavior of the operator platform will make some newlyentered companies in a very unfavorable position, which will affect the innovation power of these companies, and thus inhibit the continuous innovation of the entire Internet market.

\section{4) End-to-end transmission principles}

Network neutral supporters believe that the end-to-end transmission principle can effectively protect public resources of the internet to be fully utilized. At the same time, it can maximize the innovation potential of various content providers, and promote the fair, free, and healthy development of the Internet market.

\section{B. The Opponents of Network Neutral}

Organizations that disagree with network neutrality are mainly divided into four categories, namely, some leading companies (such as Cisco and Veri Sign) that occupy a core position in the production of network equipment, and some well-known telecom operators (such as AT\&T, China Mobile, China Telecom, etc.), some free market support groups, and large cable companies [7]. In their view, operators are also both responsible for social communications infrastructure and construction. Only by obtaining relevant returns, they will be able to obtain funds and motivation to carry out network maintenance and construction work and service upgrades. The content of the neutrality principle is not only give operators an adverse impact on the investment in the construction of basic network facilities, but also poses a serious threat to their interests. Their views are mainly reflected in the following aspects:

\section{1) Investment and innovation principles}

Scholars and related institutions that do not agree with this view believe that the mandatory setting of the policy is meaningless and will also hurt the effective deployment of network equipment, which leads to the technology not to keep pace with the times. From the perspective of economics research, profits in a certain area will decline due to the increasingly intense competition. Therefore, the implementation of network neutrality will cause investors to lose market confidence and no longer invest large amounts of investment funds in the field of network access services. Because the current network capacity can not keep up with the increasing demands of users, operators need to adopt more efficient and orderly methods, allocate resources scientifically, and actively explore new methods to reward themselves and get back their investment funds. Prepare start-up funds for the development of subsequent network technologies. With the continuous development of the Internet, network operators have the commercial power and technical strength to provide more efficient and accurate data flow services with diverse customer groups. Therefore, network operators should focus on the implementation of the differential pricing and access plans from the macro perspective. For network equipment manufacturers and telecommunications service providers, they can provide layered services [8]. This service has a form of preferential treatment. For example, according to the needs of users, online companies can provide different levels of network services. It is possible to expand the construction of bandwidth resources through value-added revenue obtained from them, and thus improve service quality.

\section{2) Unclear harm}

Since there is currently no definitive scientific argument for the impact of network neutrality, the opponents represented by Christoph You have criticized the involvement of regulation, they believe that if there is an unproven theory, it is unscientific and unreasonable to regulate in advance. Compared to the impact of Internet innovation, controlling access to the Internet does not necessarily have serious consequences when there is no evidence of harm in competition.

\section{3) The principle of property rights}

Opponents believe that the operator platform as the protagonist of participation in the Internet market, its property rights should also be recognized and respected, the mandatory implementation of network neutrality, will break the market contract, which will be detrimental to the owner's equity of the operator platform, and they cannot guarantee their social welfare. 


\section{DeVelopment Status of Network Neutral Policy IN MAJOR DEVELOPED COUNTRIES}

\section{A. The United States}

As a relatively mature country in the Internet market, the United States has many points for network neutrality that are worth learning from. Due to the particularity of its political system, network neutrality has different development patterns in different periods. At present, the U.S. polity is composed of two major parties: the Democratic Party and the Republican Party. Different parties represent different interests. The Democratic Party advocates a free market form and believes that freedom, innovation, and social equality are the normal conditions for social development. The Republican Party adheres to the principle of conservatism, emphasizes the continuity of culture and pays great attention to social stability and traditional values. Based on the different values of the two parties, their governance concepts are also different. The Democratic Party advocates that the combination of state intervention and free-market development is a guiding principle for socio-economic development. That is, it is beneficial to intervene the market by national interests and social welfare. The Republican Party advocates a completely free development of the market economy, and government intervention will only undermine the stability and durability of the market. Different governance ideas also create different attitudes toward network neutrality policies [9].

\section{1) Bush era}

As a Republican representative, Bush spoke of adopting a policy of non-regulation and laissez-faire for the Internet market. He believed that excessive supervision may affect the innovative development of the Internet market. During the Bush administration period, the debate over network neutrality focused on the legitimacy of the FCC's regulatory policies. In 2005 , the FCC formulated Internet management policies and proposed four principles for network access: First, all users had access to any legal content on the Internet. Second, in legal options, all users had the right to decide their content providers. Third, all users had the right to decide to access any network device without any impact on the network. Fourth, the competition between operators and content providers should be based on ensuring that the interests of users were not compromised.

To facilitate management, on the one hand, the FCC had formulated relevant laws and regulations, and authorized the operator platform to allow it to reject certain content provider's access according to its own needs; on the other hand, it had redefined the access service category of the operator platform. Divide it from the field of telecommunication services into the field of information services to cater the development trend of the Internet market, and require that it strictly abided by the above four principles. The above approach directly led to the rise of the network neutrality debate to the legislative level.

\section{2) The Obama era}

Obama is a representative figure of the Republican Party, and his governance concept is different from that of George W. Bush. Earlier in the election campaign, Obama promised to fully support the implementation of the Internet neutrality policy. In the early days of his administration, Obama appointed Genachowski as the new chairman of the FCC. As President Obama's highest scientific advisor, the promotion of network-neutral policy legislation had been accelerated since he took office. In July 2009, after years of disputes, the principle of network neutrality was formally incorporated into the U.S. future broadband development opportunities in the United States. This meaned that network neutrality had been implemented in the United States as a national legal policy. This principle required that all participating companies of the Internet must strictly abide by the principle of network neutrality and must not make any discriminatory actions in violation of the principle of network access. In September of the same year, the FCC added two new requirements based on the original four principles: The operator platform must not discriminate against content providers and devices accessing their networks (including discriminatory pricing and setting of priority channels. Etc.) and must implement open and transparent network management measures. This normative specification was the most extensive set of management plans with the most extensive spread content at that time.

After the FCC review, the "netwok neutrality" new regulations passed the approval in December 2010, which mainly included three principles, namely, transparency, prohibition of screening, and prohibition of any discriminatory behavior, which meaned that the operator platform should distribute its operational status, related service terms, and network management guidelines; operators in the field of video and voice services must not block legitimate application devices, services, and content; Operators must not use any discriminatory actions against suppliers for legally regulated content. In response to the FCC promulgating the Internet neutrality rule in December last year, the US House of Representatives launched its first nationwide vote in April 2011. Eventually, the proposal was rejected. The number of votes it favored and voted against was 179 and 240 votes. The introduction of the new regulations, despite prohibiting the cable and telephone service providers from discriminating against network service providers, allowed operators to adopt "reasonable" methods to deal with blocking issues in network transmission, granted operators an extraordinary fee to charge access providers in special circumstances. As of February 2015 the FCC had finally passed a new proposal for "network neutrality." The number of opposing and positive votes is 2 and 3 votes. According to the requirements of the new proposal, operators must not provide higher speed for users who paid high fees. The transmission speed, i.e., the operator may not use "paid priority." Once this proposal was put forward, it provided a powerful guarantee for the U.S. Internet becoming an independent and open trading platform. 


\section{3) Trump Times}

With the inauguration of President Trump of the United States in January 2017, the Republican Party came back to power after eight years. Like the Bush administration, President Trump is also an opponent of network neutrality. In December 2017, the U.S. Federal Communications Commission finally rejected the network neutrality policy launched by Obama during the Obama administration with three votes against and two votes in favor. On the day of the vote, the FCC issued a statement that the Obama administration's network neutrality policy would reduce investment incentives for the operator platform in network construction and obstructed the innovative behavior of small operators, mainly serving small village consumers, which is detrimental to the healthy development of the Internet.

Different interest groups hold different attitudes towards network neutrality. Network neutrality is still a standard criterion to be determined to restrict. For the future of "network neutrality," the FCC indicates that it is still exploring further.

\section{B. Europe}

In the European Internet market, due to the influence of various competitive environmental factors, it seems that the development level of its network hardware is far less than that of the United States. This narrows the scope of market competition for most operators and makes them neutral in the market. The debate is not as fierce as the United States.

In December 2009, the European Commission issued the "Telecommunications Reform Program" Regulations in its official magazine. This regulation raised issues related to network neutrality and set new rules for European network operators: The network operator was responsible for protecting user data attached to its network. When user data was damaged, it must inform the customer in advance. It was worth noting before the regulations were promulgated, network operators did not have this obligation. This showed that the European Commission intends to improve the transparency of the Internet market and prohibits network operators from implementing any discriminatory actions. This safeguards the rights of users, increases the market position of content providers and enhances their competitiveness.

In June 2010, at the EU conference held in Brussels, the European Commission, telecom operators, and various Internet companies had a profound discussion on the issue of "network neutrality." Among them, network operators claimed that charging additional fees to access companies were standard management in the industry and had been widely accepted. There was no clear evidence that this move had caused largescale discriminatory behavior. It also listed that Vodafone in Spain had already started trial pricing and the market had responded well. Implementing network neutrality policy would weaken the network operator's profitability, which was not conducive to the construction and maintenance of network facilities. Internet companies thought that network operators implementing hierarchical flow management were a discriminatory behavior. This would impair their interests. The Internet market should operate in a fair, open, and equitable manner. Network neutrality policies could achieve this vision.
On April 30th, 2016, the "Single Telecommunication Market Regulation" (from now on referred to as the "Regulations") was formally implemented in the European Union. This move was an important step for the implementation of a network neutrality policy in the European Union. The network-neutral provisions contained in the Regulations require that network operators should adhere to the "transparent, non-discriminatory and reasonable" principles. When content providers choose to access, they should leave the network neutral to leave the field, did not take any discriminatory actions, and treated the legitimate access providers equally.

In response to the telecommunication regulatory agencies of member states, EC issued the "Network Neutral Implementation Guide (Draft)" (from now on referred to as the "Guidelines") in June of the previous year, and based on the EU level; it put forward recommendations for implementation in the macro direction. During the two-month review, the number of public responses received by the "Guide" was nearly 500,000 and was officially implemented at the end of the previous year. According to the "Guide," "end-users" were classified as network-neutral beneficiaries. The "Guide" also defined the concept as follows: Firstly, consumers such as ordinary European citizens who have natural person status; Secondly, such as VoIP, video, web pages, blogs, search engines and other corporate services ,who are corporate properties and Internet content providers (CAPs). According to the relevant requirements in the Guide, the above two types of users can provide or use Internet applications or other services to independently select, access, or send out Internet content.

In accordance with the principle of network neutrality, the Guide divides the business into two categories: Internet access services refer to the provision of network access services in the field of electronic communications suitable for public use, regardless of whether they use wireless, optical or cable access methods, the use of laptops, mobile phones, tablet computers, and other access devices must all be based on the principle of network neutrality. Specific services refer to Internet access services such as teleconferencing, online video, and network medical services that can be differentiated according to service quality, application, and content. ISPs can use "specific services" without affecting the quality of the overall public network. Nominated by the customer to sign a contract and provide additional fees by providing it with priority services. Therefore, to verify whether it is only possible to provide a certain ISP's network access service by entering into a specific business contract with the customer, BEREC requires all national regulatory agencies to build a set of evaluation systems. 


\section{CONCLUSION}

The change of internet business operation model has caused network neutrality disputes. Under the background of high-speed integration of the industry. Public and private interests, conflicts and disputes between operators and Internet companies are bound to trigger this dispute. Although both parties have different ways of interpreting the status quo, there has been no real discrimination against terminal services in real life. From the perspective of empirical analysis, for the Internet companies and users, whether the violation of the principle of network neutrality will definitely bring about adverse effects, whether it will definitely affect innovation, whether or not network operators provide differentiated flow services to major content service providers is contrary to this principle, other issues need further discussion [10]. At present, discussions on the neutrality of the Internet are still in progress. The parties have not reached an agreement on this issue.

\section{REFERENCES}

[1] Byungjoon Yoo, Vidyanand Choudhary, Tridas Mukhopadhyay, A Model of Neutral B2B Intermediaries Journal of Manngment Information Systems, 2002, Vol. 19(3): pp.43-68.

[2] Hahn R and Wallsten S. The Economics of Net Neutrality[R]. The Berkeley Economic Press Economists Voice, 2006:31-39.

[3] Gao Bin. The Telecommunication Economics [M]. Beijing: People's Posts and Telecommunications Press, 2008.

[4] Frieden. Rob. A Primer on Network Neutrality. Intereconomics, 2008, Vol. 43 (1), pp.4-15。

[5] Subhajyoti. Network Netrality after Comcast Toward a Case-by-Case Approach Reasonable Penn Law, Network Management. Scholarship 2009:.55-85.

[6] Paul Ohm. When network neutrality met privacy. Commun. ACM, 2010, Vol.53.

[7] Robert Fa. Easley. Network Neutrality Versus Paid Prioritization: Analyzing the Impact on Content Innovation. Prod Oper Manag, 2016, Vol. 25(7).

[8] Ravi Mantena. Rajibl. Saha. Competition and Strategic Partnership between Intermediary Platforms in the Presence of Heterogeneous Technologies [J]. Hawaii International Conference on System Sciences, 2012: 4466-4475.

[9] Wu Liang. Legal Predicament of Network Neutrality Control and Its Outlet: From the Perspective of American Practice [J]. Global Law Review, 2015, (03): 21-27.

[10] Zou Jun. New Trends of "Net Neutrality" Controversy and Its Enlightenment [J]. Journalism \& Communication Studies, 2015, (0 6):35-39. 